\title{
VARIAÇÃO FENOTÍPICA DE POPULAÇÕES HOLOLIMNÉTICAS DE MACROBRACHIUM AMAZONICUM
}

\author{
Cunha, M.C. ${ }^{1}$, Jacobucci, G.B. ${ }^{1}$ \& Almeida, A.C. ${ }^{1}$ \\ ${ }^{1}$ Universidade Federal de Uberlândia (UFU), Campus Umuarama, Laboratório de Ecologia de Ecossistemas \\ Aquáticos - LEEA. \\ *Autor correspondente: marinaccunha@gmail.com
}

\begin{abstract}
Macrobracium amazonicum é uma espécie com distribuição continental e ocorrência em diferentes bacias hidrográficas com distintas variáveis bióticas e abióticas. Tais variáveis, principalmente abióticas, permitiram que as populações evoluíssem quanto sua genética, fisiologia, morfologia e ecologia, evidenciando M. amazonicum uma espécie referência para vários estudos. Por meio deste estudo, pretendeu-se ampliar as informações a respeito dos aspectos bioecológicos e de variação fenotípica de populações de $M$. amazonicum encontradas em dois distintos rios (R1 e R2) do Triângulo Mineiro. Durante o ano de 2017 foram realizadas 57 horas de amostragem, sendo $28 \mathrm{~h}$ com uso de covos e mais $30 \mathrm{~min}$ com uso de peneiras em cada rio. No laboratório os animais capturados foram sexados classificados em jovens e adultos quanto as classes de comprimento de carapaça $(\mathrm{CC}, \mathrm{mm})$. Entre os resultados obtidos, o mais relevante foi o fato de apenas a população de apenas um rio (R2) apresentar morfotipos de machos. Além disso, no R2, os indivíduos apresentaram maior amplitude de comprimento de carapaça (4,0 a 24,0mm) que os do R1 (4,0 a 11,0mm). Quando comparados, o CC de fêmeas jovens (FJ), adultas (FA) e ovígeras (FO), bem como de machos jovens (MJ) e adultos (MA) entre os rios, também notou-se uma diferença significativa, evidenciando que os animais do R2 tendem a ser maiores (F): ${ }_{(594)}$ $=-7,576 ; \mathrm{p}=0,00 ; \mathrm{FA}: \mathrm{t}_{(306)}=-11,076 ; \mathrm{p}=0,00 ; \mathrm{FO}: \mathrm{t}_{(35)}=-7,441 ; \mathrm{MA}: \mathrm{t}_{(233)}=-16,401 \mathrm{p}=0,00 ; \mathrm{MJ}: \mathrm{t}_{(333)}=-34,863$; $\mathrm{p}=0,00)$. A razão sexual encontrada em cada rio também foi divergente. No R1 a razão não diferiu entre os adultos $\left(\chi^{2}=0,219 ; d f=1 ; p=0,64\right)$, mas entre os jovens foi direcionada para fêmeas $\left(1: 1,22 ; \mathbb{2}^{2}=4.09 ; d f=1 ; p=0,043\right)$. No R2 houve maior proporção de fêmeas tanto entre os adultos $\left(1: 2,38 ; \chi^{2}=48,347 ; \mathrm{df}=1 ; p=0,00\right)$, quanto entre os jovens $\left(1: 2,51 ; \chi^{2}=96.492 ; \mathrm{df}=1 ; \mathrm{p}=0,00\right)$. Os animais encontrados no $\mathrm{R} 1$ apresentaram características morfológicas similares àqueles presentes na região do Pantanal (MS), mas razão sexual distinta. Já os animais do R2 assemelham-se aos hololimnéticos de grande porte localizados na região continental da Amazônia. Essa variação fenotípica, portanto, pode estar relacionada a origens genéticas distintas ou ser influenciada pela complexidade de microhabitat em ambos os rios, uma vez que as características macroambientais são equivalentes.
\end{abstract}

Palavras-chave: morfologia, Palaemonidae, razão sexual, Triângulo Mineiro.

Apoio: FAPEMIG, INBIO. 